\title{
Controle de produção industrial de plantas in vitro
}

Control of in vitro plants on industrial production

\author{
JOSÉ BARBOSA CABRAL
}

A qualidade fitossanitária e genética de mudas micropropagadas in vitro na área de fruticultura e de floricultura são temas incorporados no estado atual da agricultura moderna.

O produtor rural e/ou o empresário agrícola, deve minimizar os níveis de riscos causados na implantação de um projeto agrícola. A muda representa um dos principais insumos, tanto pelo custo de implantação do projeto quanto pela garantia de sucesso esperado no investimento e na oferta de produtos de boa qualidade para o mercado consumidor nacional e internacional.

Nesta direção o processo industrial de produção de mudas de espécies vegetais micropropagadas in vitro em uma biofábrica de plantas é sem dúvida uma atividade que exige muito critério técnico no controle de qualidade fitossanitária e genética das mudas produzidas, na escolha de plantas matrizes para o estabelecimento e introdução dos explantes sob condições in vitro, certificação e indexação de patógenos sistêmicos (bactérias, vírus, outros), manipulação, controle da morfogênse e produção em larga escala da cultivar e/ou do híbrido desejado.

O sucesso de uma biofábrica depende dos seguintes fatores básicos:

1) Conhecimento da tecnologia a ser empregada no processo produtivo;

2) Capacidade de gerenciamento administrativo.

O princípio básico teórico de que qualquer espécie vegetal para ser multiplicada sob condições in vitro é a "totipotência celular".

As espécies vegetais mais utilizadas nos processos de multiplicação industriais em biofábricas são: as plantas ornamentais para flores de corte e vasos (orquídeas, gérberas, antúrios, e outras), espécies de plantas utilizadas como folhagens e na fruticultura (banana, abacaxi, e, outras).

O estabelecimento de uma biofábrica de plantas requer elevado nível de investimentos em estrutura de laboratórios, estufas e telados, sem deixar de considerar a questão da mão-de-obra especializada.

No processo de produção de mudas in vitro em larga escala pode-se enfrentar alguns problemas:

1) Contaminação;

2) Mutações;

3) Desordens fisiológicas;

4) Planejamento inadequado do processo produtivo.

Em nosso país um dos problemas enfrentados no mercado de mudas micropropagadas in vitro é a pirataria, na produção de mudas de espécies de flores de corte (gérberas, antúrios e outras), tanto no aspecto da oferta de mudas por laboratórios não credenciados por Programas de Melhoramento Genéticos (Nacional e/ou Internacional) quanto pela multiplicação assexuada (divisão de touceira) de material genético superior pelos produtores, o que efetivamente compromete a qualidade da muda e o nível de receita do produtor. Isso ocorre porque a qualidade fitossanitária dessa muda fica comprometida, devido a disseminação de pragas e doenças sistêmicas como vírus, bactérias nos plantios, afetando a produtividade da cultura e a qualidade do produto final. No aspecto da qualidade genética, em laboratórios não credenciados de micropropagação in vitro, predomina a falta de critérios técnicos de números de repicagem permitida, podendo oferecer ao mercado uma muda com níveis de variação genética "somaclonal" não tolerado.

No Brasil o controle de produção de mu- 
das é regularizado pelo órgão controlador, o Ministério de Agricultura, Pecuária e Abastecimento - MAPA, através da LEI N. ${ }^{\circ} .10 .711$ de 05 de agosto de 2003, seguida pelo Decreto N. ${ }^{\circ} .5 .153$ de 23 de julho de 2004, essa lei estabelece a obrigatoriedade de que todos os materiais vegetais multiplicados, propagados, comercializados sejam registrados nesse órgão (CNCR-MAPA) , estabelecendo uma ordem no comércio de sementes e mudas em nosso país. Por outro lado, em relação a "proteção de cultivares", no Brasil ainda existem muitas limitações, porque, o uso de uma tecnologia (variedades de plantas) em relação aos direitos intelectuais de uma pessoa e/ ou uma empresa é controlada através da LEI DE PROTEÇÃO DE CULTIVARES N. ${ }^{\circ} .456$ de 25 de abril de 1997, do MAPA, publicada no DOU em 28/04/97, seguida pelo Decreto N. ${ }^{\circ} .366$ de 5 de novembro de 1997, publicado no DOU em 07/11/97, não é tão evoluída para condenar os infratores como em países desenvolvidos com as suas leis de patentes, e, com isso esse mercado de mudas pirateadas tem muita expressão em nosso país.

No Estado de Pernambuco, a Biolab Tecnologia Vegetal Ltda, está sediada na BR 101 Norte, km 17, Itapirema, no Município de Goiana, Pernambuco, numa Estação Experimental da Empresa Pernambucana de Pesquisa Agropecuária - IPA, tem trabalhado atendendo todos os critérios e normas técnicas estabelecidas nacionalmente $\mathrm{e}$ internacionalmente produzindo mudas micropro- pagadas in vitro de espécies vegetais na área de Fruticultura, várias cultivares/híbridos (tetraplóides) de banana, abacaxi, na área de Plantas Ornamentais com espécies de abacaxi ornamental (Ananas lucidus, Ananas bracteatus e outras), gérberas de corte (Gerbera jamesonii) e antúrio (Anthurium andraeanum Lindl.), sendo o último mais recentemente, e, na área de Culturas Industriais com cana-de-açúcar (Saccharum spp.) em convênio com algumas Usinas e Destilarias.

A BIOLAB mantém convênios de parceria com o IPA, IAC, EMBRAPA Mandioca e Fruticultura - CNPMF, Universidade Federal de Alagoas - UFAL, Universidade Federal Rural de Pernambuco - UFPE, COPERSUCAR, BINDI SIRIO (Itália) e a SUN WORLD (U.S. A).

O convênio com o IAC nos permite trabalhar com as variedades de antúrio lançadas por essa Instituição, com a EMBRAPA-CNPMF, possibilita a produção de mudas de banana com os híbridos (tetraplóides) resistentes a Sigatoka Negra, com a UFRPE e UFAL a produção de mudas meristemáticas de cana-de-açúcar da sigla RB, com a COPERSUCAR a multiplicação de variedades de cana-de-açúcar da sigla SP, com a BINDI SIRIO a micropropagação in vitro de mudas de gérberas de corte e com a SUN WORLD a produção de mudas de uva sem sementes (fase inicial). 